\title{
Molecular identification and expression patterns of odorant binding protein and chemosensory protein genes in Athetis lepigone (Lepidoptera: Noctuidae)
}

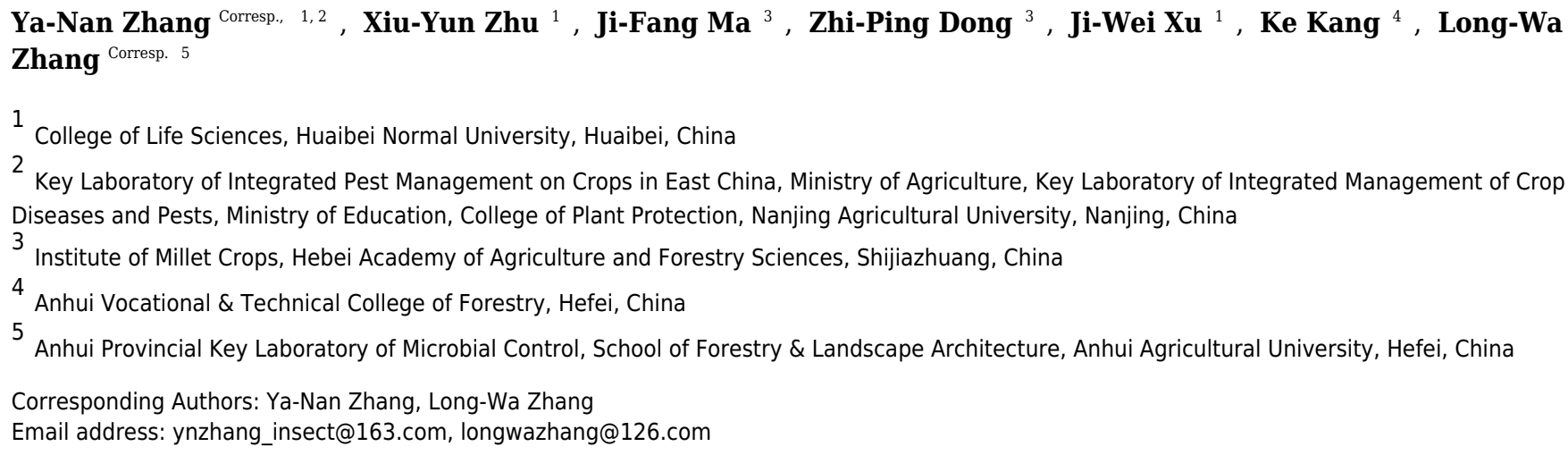

The olfaction system of insects plays an important role in mediating various physiological behaviors, including locating hosts, avoiding predators, and recognizing mates and oviposition sites. Therefore, some key genes in the system present valuable opportunities as targets for developing novel green pesticides. Athetis lepigone, a noctuid moth can feed on more than 30 different host plants making it a serious polyphagous pest worldwide, and it has become one of the major maize pests in northern China since 2011. However, there are no reports on effective and environmentally friendly pesticides for the control of this pest. In this study, we identified 28 genes encoding putative odorant binding proteins (OBPs) and 20 chemosensory protein (CSPs) genes based on our previous $A$. lepigone transcriptomic data. A tissue expression investigation and phylogenetic analysis were conducted in an effort to postulate the functions of these genes. Our results show that nearly half (46.4\%) of the AIOBPs exhibited antennae-biased expression while many of the AICSPS were highly abundant in non-antennal tissues. These results will aid in exploring the chemosensory mechanisms of $A$. lepigone and developing environmentally friendly pesticides against this pest in the future. 
1 Molecular identification and expression patterns of odorant binding

2 protein and chemosensory protein genes in Athetis lepigone (Lepidoptera:

3 Noctuidae)

4

5 Ya-Nan Zhang ${ }^{1,2 *}$, Xiu-Yun Zhu ${ }^{1}$, Ji-Fang Ma ${ }^{3}$, Zhi-Ping Dong ${ }^{3}$, Ji-Wei $\mathrm{Xu}^{1}$, Ke Kang ${ }^{4}$, Long6 Wa Zhang ${ }^{5 *}$

7

8 1. College of Life Sciences, Huaibei Normal University, Huaibei, China

9 2. Key Laboratory of Integrated Pest Management on Crops in East China, Ministry of

Running head: OBP and CSP genes of Athetis lepigone

authors:

ynzhang insect@163.com

(Ya-Nan Zhang); 


\section{Abstract}

24 The olfaction system of insects plays an important role in mediating various physiological 25 behaviors, including locating hosts, avoiding predators, and recognizing mates and oviposition 26 sites. Therefore, some key genes in the system present valuable opportunities as targets for

27 developing novel green pesticides. Athetis lepigone, a noctuid moth can feed on more than 30 28 different host plants making it a serious polyphagous pest worldwide, and it has become one of the major maize pests in northern China since 2011. However, there are no reports on effective and environmentally friendly pesticides for the control of this pest. In this study, we identified 28 genes encoding putative odorant binding proteins (OBPs) and 20 chemosensory protein (CSPs) genes based on our previous A. lepigone transcriptomic data. A tissue expression investigation and phylogenetic analysis were conducted in an effort to postulate the functions of these genes. Our results show that nearly half (46.4\%) of the AlOBPs exhibited antennae-biased expression while many of the AlCSPs were highly abundant in non-antennal tissues. These results will aid in exploring the chemosensory mechanisms of A. lepigone and developing environmentally friendly pesticides against this pest in the future. 


\section{INTRODUCTION}

45

46

47

The olfaction system of insects mediates a host of physiological behaviors, such as host location, predator avoidance, and mate and oviposition site recognition (Leal 2013). Many studies show that the periphery process of insect olfaction requires a set of genes, including those that encode odorant binding proteins (OBPs), chemosensory proteins (CSPs), and chemosensory receptors (Elfekih et al. 2016; Glaser et al. 2015; Larter et al. 2016; Li et al. 2015; Paula et al. 2016; Zhang et al. 2013). Generally, OBPs/CSPs located in the antennal sensillar lymph can recognize and bind external odorants that can then be transferred by OBPs/CSPs through the sensillar lymph to chemosensory receptors, odorant receptors (ORs) and ionotropic receptors (IRs). Therefore, OBPs and CSPs play key roles in helping insects recognize various odorants and regulate their behaviors (Dani et al. 2011; Zhou 2010). These functions also suggest that these protein families may present valuable opportunities as target genes for developing novel green pesticides.

Insect OBPs are a class of small, abundant, and water-soluble extracellular proteins of $\sim 14$ KDa. Most OBPs use six positionally conserved cysteines to form three interlocking disulphide bridges that stabilize the protein's three-dimensional structure (Lagarde et al. 2011; Leal et al. 1999; Pelosi \& Maida 1995; Vogt \& Riddiford 1981). Since the first OBP was identified in Antheraea polyphemus (Vogt \& Riddiford 1981), many OBPs have been found in various insects based on genomic or transcriptomic methods in recent years. Based on the structural features and similarity in protein sequences, insect OBPs can be divided into three major subclasses ( $\mathrm{Li}$ et al. 2013; Schultze et al. 2012; Spinelli et al. 2012; Zhou 2010): Classic OBPs, including pheromone binding proteins (PBPs), general odorant binding proteins (GOBPs), and two OBPs involved in the recognition of female sex pheromones and host volatiles; plus-C OBPs; and minus-C OBPs, which may also participate in the binding of host volatiles as suggested by an in vitro competitive binding assay.

Olfactory specific protein D (OS-D), the first insect CSP gene, was discovered in Drosophila melanogaster (McKenna et al. 1994). By using similar methods as for OBP identification, many CSPs have been discovered in distinct insects (Guo et al. 2011; Iovinella et al. 2013; Jacquin- 
Joly et al. 2001; Liu et al. 2010; Missbach et al. 2015; Picimbon et al. 2001; Wanner et al. 2004). Unlike OBPs, CSPs are smaller and more conserved in distinct insects, which only have four conserved cysteines that form two interlocking disulphide bridges (Bohbot et al. 1998; Lartigue et al. 2002; Maleszka \& Stange 1997; Pelosi et al. 2005; Zhang et al. 2014). Furthermore, OBPs are usually specifically or predominately expressed in the antennae, whereas many CSPs are expressed in the antennae and other tissues (Pelosi et al. 2005; Vogt 2005; Zhang et al. 2016a; Zhang et al. 2013), suggesting insect CSPs have both chemosensation and non-chemosensation functions as is illustrated by their association with chemosensation in moths (Jacquin-Joly et al. 2001; Sun et al. 2015; Zhang et al. 2014), limb regeneration in Periplaneta eparate (Nomura et al. 1992), embryo development in Apis mellifera (Maleszka et al. 2007), behavioral phase change in Locusta migratoria (Guo et al. 2011), and female moth survival and reproduction in Spodoptera exigua (Gong et al. 2012).

Athetis lepigone Möschler (Lepidoptera: Noctuidae) is a serious polyphagous pest found worldwide (Fu et al. 2014; Karsholt et al. 2013; Lindeborg 2008; Nikolaevitch \& Vjatcheslavovna 2003; Zhang et al. 2009) that can feed on more than 30 different host plants species and has become one of the major maize pests in northern China since 2011 (Jiang et al. 2011; Ma et al. 2012; Shi et al. 2011). However, there are no reports on the chemosensory mechanism mediated by OBPs/CSPs between the pests and host plants. In this study, we identified 28 and 20 genes encoding putative AlOBPs (A. lepigone OBPs) and AlCSPs ( $A$. lepigone CSPs), respectively, based on our previous transcriptomic data of A. lepigone (Zhang et al. 2016b). Tissue expression and phylogenetic analyses were conducted in an effort to postulate the function of these genes. We found that most AlOBPs and AlCSPs had high identities with those in other moths (Campanacci et al. 2001; Gu et al. 2013; Liu et al. 2015c; Zhang et al. 2015a; Zhang et al. 2013; Zhang et al. 2015b); nearly half of the AlOBPs exhibited antennaebiased expression, and many AlCSPs were found in various tissues and were highly expressed in proboscises, legs, and wings, which will help us explore the chemosensory mechanism of $A$. lepigone and develop environmentally friendly pesticides against this pest in the future. 
99

100

101

102

103

104

105

106

107

108

109

110

111

112

113

114

115

116

117

118

119

120

121

122

123

124

\section{MATERIALS \& METHODS}

\section{Insect rearing and tissue collection}

A. lepigone were fed an noctuid artificial diet (Huang et al. 2002) at a temperature of $26 \pm 1{ }^{\circ} \mathrm{C}$ in a 14:10 h, light:dark photoperiod. Pupae were sexed, and males and females were placed into separate enclosures. Adult moths were given a 10\% honey solution after emergence. We collected 25-30 female antennae (FA), 25-30 male antennae (MA), 50-60 proboscises (Pr,

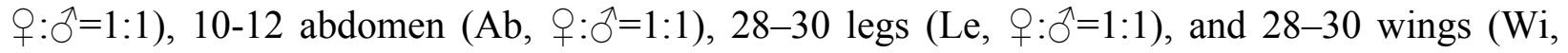
$q: \hat{O}=1: 1)$ from three-day-old virgin adults. All samples were immediately frozen in liquid nitrogen and stored at $-80{ }^{\circ} \mathrm{C}$ until use.

\section{RNA isolation and cDNA synthesis}

Total RNA was extracted using the MiniBEST Universal RNA Extraction Kit (TaKaRa, Dalian, China) following the manufacturer's instructions, and the RNA quality was checked using a spectrophotometer (NanoDrop ${ }^{\mathrm{TM}}$ 2000, Thermo Fisher Scientific, USA). The single-stranded cDNA templates were synthesized from $1 \mu \mathrm{g}$ total RNA from various tissue samples using the PrimeScript ${ }^{\mathrm{TM}}$ RT Master Mix (TaKaRa, Dalian, China).

5

\section{Sequence analyses}

The open reading frames (ORFs) of the putative chemosensory genes were predicted using ORF Finder (http://www.ncbi.nlm.nih.gov/gorf/gorf.html). The similarity searches were performed with NCBI-BLAST (http://blast.ncbi.nlm.nih.gov/). Putative N-terminal signal peptides for AlOBPs and AlCSPs were predicted by SignalP 4.1 (http://www.cbs.dtu.dk/services/SignalP/) (Petersen et al. 2011).

\section{Phylogenetic analysis}

Phylogenetic trees were reconstructed for the analysis of $A l O B P \mathrm{~s}$ and $A l C S P \mathrm{~s}$, based on the gene 
125

126

127

128

129

130

131

132

133

134

135

136

137

138

139

140

141

142

143

144

145

146

147

148

149

150

151

sequences of A. lepigone and those of other insects. The OBP data set contained 28 sequences from A. lepigone (Table S1), and 100 from other insects including Bombyx mori (Gong et al. 2009), Manduca sexta (Grosse-Wilde et al. 2011), Sesamia inferens (Zhang et al. 2013), and Spodoptera littoralis (Legeai et al. 2011). The CSP dataset contained 20 sequences from $A$. lepigone (Table S1) and 68 from other insects including B. mori (Gong et al. 2007), M. sexta (Grosse-Wilde et al. 2011), S. inferens (Zhang et al. 2013), and S. littoralis (Legeai et al. 2011). $\begin{array}{lllllll}\text { Amino acid sequences were aligned with } & \text { MAFFT version } 7\end{array}$ (http://mafft.cbrc.jp/alignment/server/), and phylogenetic trees were constructed using PhyML (Guindon et al., 2010) based on the LG substitution model (Le and Gascuel, 2008) with Nearest Neighbour Interchange (NNI), and branch support estimated by a Bayesian-like transformation of the aLRT (aBayes) method. Dendrograms were created and colored in FigTree (http://tree.bio.ed.ac.uk/software/figtree/).

\section{Quantitative real time-PCR}

Expression profiling of $A l O B P S$ and $A l C S P S$ was performed using quantitative real time-PCR (qRT-PCR) performed in a LightCycler ${ }^{\circledR} 96$ (Roche, Switzerland) with a mixture of $5 \mu \mathrm{L} 2 \mathrm{X}$ $\mathrm{SYBR}^{\circledR}$ Premix Ex Taq (Tli RNaseH Plus) (TaKaRa, Dalian), $0.2 \mu \mathrm{L}$ of each primer $(10 \mu \mathrm{M})$, $2.5 \mathrm{ng}$ of sample cDNA, and $3.6 \mu \mathrm{L}$ of sterilized ultrapure $\mathrm{H}_{2} \mathrm{O}$. The reaction program was as follows: $30 \mathrm{~s}$ at $95^{\circ} \mathrm{C}, 40$ cycles of $95^{\circ} \mathrm{C}$ for $5 \mathrm{~s}$, and $60^{\circ} \mathrm{C}$ for $20 \mathrm{~s}$. The results were analyzed using a LightCycler ${ }^{\circledR} 96 \mathrm{SW}$ 1.1. The qRT-PCR primers (Table S2) were designed with Beacon Designer 7.9 (PREMIER Biosoft International, CA, USA). This was followed by the measurement of fluorescence over a 55 to $95{ }^{\circ} \mathrm{C}$ melting curve to detect a single gene-specific peak and to check the absence of primer dimer peaks, and a single and discrete peak was detected for all primers tested. Negative controls consisted of non-template reactions where the cDNA was replaced with $\mathrm{H}_{2} \mathrm{O}$.

Expression levels of $A l O B P s$ and $A l C S P S$ were calculated relative to the reference genes AlGAPDH (A. lepigone glyceraldehyde-3-phosphate dehydrogenase) and AlEF (A. lepigone 
152

153

154

155

156

157

158

159

160

161

162

163

164

165

166

167

168

169

170

171

172

173

174

175

176

177

178

elongation factor-1 alpha) using the Q-Gene method in the Microsoft Excel-based software Visual Basic (Muller et al. 2002; Simon 2003). For each sample, three biological replicates were performed with three technical replicates per biological replicate.

\section{Statistical analysis}

Data (mean $\pm \mathrm{SE}$ ) from various samples were subjected to one-way nested analysis of variance (ANOVA) followed by a least significant difference test (LSD) for mean comparisons using the SPSS Statistics 22.0 software (SPSS Inc., Chicago, IL, USA).

\section{RESULTS}

\section{Identification of putative $\mathrm{OBP}$ genes in $A$. lepigone}

Based on our previous antennal transcriptomic data (NCBI-SRX number: 2543665) for $A$. lepigone (Zhang et al. 2016b), we first identified 28 genes encoding putative OBPs including three $P B P \mathrm{~s}$ and two GOBPs (Table 1). Among the $28 A l O B P \mathrm{~s}, 24$ sequences were predicted to be full-length genes that encoded 133 to 246 amino acids; all 24 genes had a predicted signal peptide at the N-terminus. According to the number and position of conserved cysteines, insect OBPs can be divided into different subclasses: Classic OBPs, Plus-C OBPs, and Minus-C OBPs (Zhou 2010). Here, AlOBP4 and AlOBP9 had no conserved cysteines at the $\mathrm{C} 2$ and $\mathrm{C} 5$ positions, and, therefore, belonged to the Minus-C OBP subfamily; AlOBP2, AlOBP7, and AlOBP14 had cysteines in addition to the six conserved cysteines; therefore, they belonged to the Plus-C OBP subfamily; the other 19 full-length AlOBPs belonged to the Classic OBP subfamily, which had six conserved cysteines at the corresponding positions (Fig. S1).

\section{Identification of putative CSP genes in A. lepigone}

Twenty putative genes encoding CSPs were identified in A. lepigone via antennal transcriptome analysis (Table 2). Eighteen of these had full length ORFs with 4 conserved cysteines in corresponding positions (Fig. S2), and seventeen genes (except AlCSP14) had a predicted signal 
179 180

peptide at the N-terminus. The results of a BLASTX match showed that $80 \%$ of these CSPs $(n=16)$ had $>70 \%$ identity with other CSPs from different moths and that this was higher than the sequence identities of the OBPs (75\%) (Table 2).

\section{Phylogenetic analyses of moth OBPs and CSPs}

Two phylogenetic trees, one of moth OBPs and one of moth CSPs, were constructed using protein sequences from A. lepigone, B. mori, S. inferens, S. littoralis, and M. sexta, (Fig. 1 and Fig. 2). Similar to other studies (He et al. 2010; Pelosi et al. 2014b; Vogt et al. 1991; Xiu \& Dong 2007), the OBP tree showed that moth OBPs can be divided into PBP/GOBP, Minus-C OBP, and Plus-C OBP subfamilies. AlPBP1-3 clustered into the PBP subfamily and the AlGOBPs (1 and 2) clustered into the GOBP subfamily. Two AlOBPs (AlOBP4 and AlOBP9) clustered into the moth Minus-C OBP subfamily, and four AlOBPs (AlOBP2, AlOBP7, AlOBP10, and AlOBP14) clustered into the moth Plus-C OBP subfamily. The rest of the AlOBPs clustered with at least one orthologous moth gene. In the constructed CSP tree, our results indicated that all 20 AlCSPs were distributed along various branches and each clustered with at least one other moth ortholog.

\section{OBPs and CSPs expression patterns in A. lepigone}

We used the qRT-PCR results to investigate the expression profiles of all AlOBPs and AlCSPs. The results showed that all the OBPs and CSPs were expressed in the adult antennae of $A$. lepigone. Among the $28 \mathrm{AlOBPs}, 13 \mathrm{AlOBPs}$ (including PBPs and GOBPs) were significantly highly expressed in the antennae ( $p<0.05$, ANOVA, LSD), including 5 male-biased (AlPBPI, $A l P B P 2, A L O B P 6, A l O B P 17$, and $A l O B P 20)$ and 3 female-biased (AlOBP1,AlOBP3, and $A l O B P 19)$ OBP genes. In all $28 A l O B P s, A l G O B P 1$ and $A l P B P 1$ (male antennae) exhibited the highest expression levels, and AlOBP19 exhibited the lowest expression abundance (Fig. 3). In addition, eight $\operatorname{AlOBPs}(\operatorname{AlOBP} 4,8,11,14,16,21,22$, and 23) exhibited proboscis-biased expression, $A l O B P 10$ was expressed significantly more in the adult abdomen, and four $A l O B P \mathrm{~s}$ $(A l O B P 2,9,13$, and 18$)$ displayed higher expression levels in adult wings than in other tissues 
207

208

209

210

211

212

213

214

215

216

217

218

219

220

221

222

223

224

225

226

227

228

229

230

231

232

233

(Fig. 3).

Compared to $A l O B P \mathrm{~s}, A l C S P_{\mathrm{s}}$ were highly expressed in adult antennae as well as in nonantennae tissues. Of the 20 identified AlCSP genes, only AlCSP2, AlCSP6, and AlCSP18 had antennae-biased expression; AlCSP2 was male-biased and AlCSP18 was female-biased in their expression. Six AlCSP genes (AlCSP1, 9, 12, 15, 16 and 20) were highly expressed in the proboscises, and nine (AlCSP3-5, 7, 8, 10, 13, 14 and 19) were highly expressed in the wings; among the 20 total AlCSPs, AlCSP14 and AlCSP5 displayed the highest and lowest expression levels in the antennae, respectively (Fig. 4).

\section{DISCUSSION}

In this study, we first identified 28 and 20 genes encoding putative AlOBPs and AlCSPs, respectively, based on our previous A. lepigone transcriptomic data (Zhang et al. 2016b). The number of $A l O B P$ and AlCSP genes identified for this species are similar to some reported moths, such as C. suppressalis (Cao et al. 2014), H. armigera (Liu et al. 2012), and B. mori (Gong et al. 2007), but there are certain different from S. litura (Gu et al. 2015), S. inferens (Zhang et al. 2013), H. armigera (Liu et al. 2012) and B. mori (Gong et al. 2009). The reasons for the differences in gene number may be due to: 1) the different chemosensory behaviors of different moths requiring distinct molecular mechanisms that have developed over evolutionary time; 2) the genomic data will help us identify more genes from $A$. lepigone as well as from other moths in the future.

Many studies have shown that insect OBPs are mainly expressed in the antennae of both sexes and that they may play key roles in the process of host location, mating, and oviposition by allowing the insect to accurately recognize environmental odorants (Larter et al. 2016; Leal 2013; Qiao et al. 2009; Zhou et al. 2009). The phylogenetic tree of moth OBPs showed that AlOBPs were divided into different subfamilies, including the PBP/GOBP, Minus-C OBP, and Plus-C OBP proteins suggesting that the structural diversity of AlOBPs may be involved in chemosensation and/or in other physiological processes. Based on the qRT-PCR analyses, we 
234 found that $46 \%$ of the $28 \mathrm{AlOBPs}$ were highly expressed in the antennae indicating that these

235

236

237

238

239

240

241

242

243

244

245

246

247

248

249

250

251

252

253

254

255

256

257

258

259

260

AlOBP proteins have putative roles in the odorant reorganization of $A$. lepigone. Similar to our previous work and to other studies (Gu et al. 2015; McKenzie et al. 2014; Zhang et al. 2016a; Zhang et al. 2013), we found that there were five $A l O B P$ genes highly expressed in non-antennal tissues (legs and wings), including one abdomen-biased AlOBP-encoding gene and four wingbiased $A l O B P$ genes, indicating that these OBPs may have other non-chemosensory functions.

Five AlPBP/GOBPs displayed higher expression in the adult antennae (especially AlGOBP1 and AlPBP1), which is consistent with that reported for PBP/GOBPs in other moths (Liu et al. 2013; Liu et al. 2015b; Zhang et al. 2013). According to recent functional studies of moth PBP/GOBPs (Jin et al. 2014; Liu et al. 2015a; Liu et al. 2013; Sun et al. 2013; Zhu et al. 2016) and D. melanogaster LUSH protein (OBP76a) (Ha \& Smith 2006; Stowers \& Logan 2008; Zhou et al. 2004), we hypothesize that the AlPBP/GOBPs may also play important roles in recognizing the sex pheromones of female moths and some host plant volatiles. Additionally, there are three male-biased and three female-biased AlOBP genes, indicating that these sex-biased OBPs may participate in the reorganization of female or male sex pheromones, plant volatiles from oviposition sites, or other sex-related odorants, and need further analysis to explore their exact roles such as through fluorescence competitive binding assays (Liu et al. 2015b), CRISPR/Cas9 mediated genome editing (Zhu et al. 2016), and gene mutations (Stowers \& Logan 2008).

Studies on CSP genes in certain insects have shown that they are smaller and more conserved than $O B P$ genes and that they are widely expressed in different parts of the insect body (Calvello et al. 2005; Gong et al. 2007; Pelosi et al. 2014a; Zhang et al. 2013). Our BLASTX results showed that the AlCSPs had relatively high identities with other moth CSPs indicating high conservation of CSPs among moths. Our results agreed with those from studies using ligandbinding assays that found that some CSPs in other Lepidopterans have chemosensory roles including in Mamestra brassicae (Jacquin-Joly et al. 2001), B. mori (Qiao et al. 2013), and S. inferens (Zhang et al. 2014). Compared to the AlOBP genes highly expressed in the antennae, only three AlCSPs had antennae-biased expression, indicating that these three genes may be 
261 involved in the recognition and transmission of sex pheromones, host volatiles, and other 262 odorants. On the other hand, many insect CSPs are broadly expressed in non-chemosensory 263 tissues and have non-chemosensory functions, such as SexiCSP3, which has been shown to have 264 effects on the survival and reproduction of S. exigua (Gong et al. 2012), and AmelCSP5, which

265 is involved in embryonic integument formation in A. mellifera (Foret et al. 2007). In this study, many $A l C S P$ s were found in various tissues and were highly expressed in non-chemosensory tissues suggesting that these AlCSPs (especially AlCSP14, which had the highest expression) may be involved in other physiological functions apart from chemosensory ones.

Furthermore, we found that there were eight AlOBPs (28.5\% of all AlOBPs) and six AlCSPS (30.0\% of all AlCSPs) that displayed proboscis-biased expression. OBP and CSP gene expression in the proboscis has been observed in other insects including Apolygus lucorum (Hua et al. 2012), Lygus lineolaris (Hull et al. 2014), S. podoptera (Liu et al. 2015c), and A. dissimilis (Sun et al. 2016). Further functional studies have also confirmed the gustation function of some genes: OBP49a in D. melanogaster is involved in the suppression of sweet taste by bitter chemicals (Jeong et al. 2013); some OBPs in D. melanogaster can modulate sucrose intake in response to a panel of nine bitter compounds by RNAi-mediated methods (Swarup et al. 2014); and CSP4, which is exclusively presented in the proboscis of two sibling species - H. armigera and $H$. assulta - an act as a wetting agent to reduce the surface tension of aqueous solutions (Liu et al. 2014). Therefore, the 14 AlOBPs and AlCSPs with proboscis-biased expression may play similar gustation functions in A. lepigone.

In the future, these AlOBPs and AlCSPs can help us develop environmentally friendly pesticides against $A$. lepigone based on reverse chemical ecology (Dominguez et al. 2016; Zhou 2010). We can explore the functions of candidate OBPs/CSPs in vitro to screen compounds with high binding affinities (e.g., host plant volatiles or sex pheromones) to target the OBPs/CSPs. These compounds could then be investigated as potential pesticides or sexual attractants. Further, with genetic modification by the CRISPR/Cas9 editing system (Hsu et al. 2014; Li et al. 2016; Zhu et al. 2016), we can knock out the candidate OBPs and CSPs to construct various mutant 
288

289

290

291

292

293

294

295

296

297

298

299

300

301

302

303

304

305

306

307

308

309

310

311

312

313

strains and then release the effective strains into the field to disrupt the chemical communication behaviors of the pest.

\section{CONCLUSION}

In conclusion, we identified an extensive set of putative OBP- and CSP-encoding genes in $A$. lepigone based on our previous antennal transcriptomic data. As the first step towards understanding the functions of these genes, we conducted comprehensive and comparative phylogenetic analyses and developed gene expression profiles for OBPs and CSPs and found that most of the AlOBPs and AlCSPs had high identities with other moth odorant genes. Nearly half of the $A l O B P$ s displayed antennae-biased expression, but many AlCSPs were detected in all tissues tested and were highly expressed in non-antennal tissues. Understanding the tissue and sex-biased expression patterns will help identify the functions of AlOBPs and AlCSPs, which in turn will aid in elucidating the chemosensory mechanism of A. lepigone and developing environmentally friendly pesticides against this pest in future.

\section{ACKNOWLEDGEMENTS}

We thank Master students Mei-Yan Zheng (Nanjing Agricultural University, China), Bachelor students Cai-Yun Yin and Meng-Ya Li (Huaibei Normal University, China) for their help in collecting insects, and Dr. Peng He (Guizhou University, China) for suggestions to improve the manuscript.

\section{ADDITIONAL INFORMATION AND DECLARATIONS}

\section{Data Availability}

The following information was supplied regarding data availability: The sequences of AlOBPs and AlCSPs have been supplied as Supplemental Information. 
314 Supplemental information for this article can be found online.

315

316

317

318

319

320

321

322

323

324

325

326

327

328

329

330

331

332

333

334

335

336

337

338

339

340

341

342

343

344

345

346

347

348

349

350

351

352

\section{References}

Bohbot J, Sobrio F, Lucas P, and Nagnan-Le Meillour P. 1998. Functional characterization of a new class of odorantbinding proteins in the moth Mamestra brassicae. Biochem Biophys Res Commun 253:489-494. S0006291X(98)99806-0 [pii]

10.1006/bbrc.1998.9806

Calvello M, Brandazza A, Navarrini A, Dani FR, Turillazzi S, Felicioli A, and Pelosi P. 2005. Expression of odorantbinding proteins and chemosensory proteins in some Hymenoptera. Insect Biochem Mol Biol 35:297-307. S0965-1748(05)00005-6 [pii]

10.1016/j.ibmb.2005.01.002

Campanacci V, Krieger J, Bette S, Sturgis JN, Lartigue A, Cambillau C, Breer H, and Tegoni M. 2001. Revisiting the specificity of Mamestra brassicae and Antheraea polyphemus pheromone-binding proteins with a fluorescence binding assay. J Biol Chem 276:20078-20084. 10.1074/jbc.M100713200

M100713200 [pii]

Cao D, Liu Y, Wei J, Liao X, Walker WB, Li J, and Wang G. 2014. Identification of candidate olfactory genes in Chilo suppressalis by antennal transcriptome analysis. Int J Biol Sci 10:846-860. 10.7150/ijbs.9297

ijbsv10p0846 [pii]

Dani FR, Michelucci E, Francese S, Mastrobuoni G, Cappellozza S, La Marca G, Niccolini A, Felicioli A, Moneti G, and Pelosi P. 2011. Odorant-binding proteins and chemosensory proteins in pheromone detection and release in the silkmoth Bombyx mori. Chem Senses 36:335-344. bjq137 [pii]

10.1093/chemse/bjq137

Dominguez A, Puigmarti M, Bosch MP, Rosell G, Crehuet R, Ortiz A, Quero C, and Guerrero A. 2016. Synthesis, functional assays, electrophysiological activity, and field tests of pheromone antagonists of the tomato leafminer, Tuta absoluta. J Agric Food Chem 64:3523-3532. 10.1021/acs.jafc.6b00674

Elfekih S, Chen CY, Hsu JC, Belcaid M, and Haymer D. 2016. Identification and preliminary characterization of chemosensory perception-associated proteins in the melon fly Bactrocera cucurbitae using RNA-seq. Sci Rep 6:19112. 10.1038/srep19112

Foret S, Wanner KW, and Maleszka R. 2007. Chemosensory proteins in the honey bee: Insights from the annotated genome, comparative analyses and expressional profiling. Insect Biochem Mol Biol 37:19-28. S09651748(06)00189-5 [pii]

10.1016/j.ibmb.2006.09.009

Fu X, Liu Y, Li Y, Ali A, and Wu K. 2014. Does Athetis lepigone moth (Lepidoptera: Noctuidae) take a long-distance migration? J Econ Entomol 107:995-1002.

Glaser N, Gallot A, Legeai F, Harry M, Kaiser L, Le Ru B, Calatayud PA, and Jacquin-Joly E. 2015. Differential expression of the chemosensory transcriptome in two populations of the stemborer Sesamia nonagrioides. Insect Biochem Mol Biol 65:28-34. 10.1016/j.ibmb.2015.07.008

Gong DP, Zhang HJ, Zhao P, Lin Y, Xia QY, and Xiang ZH. 2007. Identification and expression pattern of the 
353

354

355

356

357

358

359

360

361

362

363

364

365

366

367

368

369

370

371

372

373

374

375

376

377

378

379

380

381

382

383

384

385

386

387

388

389

390

391

392

393

chemosensory protein gene family in the silkworm, Bombyx mori. Insect Biochem Mol Biol 37:266-277. S0965-1748(06)00250-5 [pii]

10.1016/j.ibmb.2006.11.012

Gong DP, Zhang HJ, Zhao P, Xia QY, and Xiang ZH. 2009. The odorant binding protein gene family from the genome of silkworm, Bombyx mori. BMC Genomics 10:332. 1471-2164-10-332 [pii]

10.1186/1471-2164-10-332

Gong L, Luo Q, Rizwan-Ul-Haq M, and Hu MY. 2012. Cloning and characterization of three chemosensory proteins from Spodoptera exigua and effects of gene silencing on female survival and reproduction. Bull Entomol Res 102:600-609. S0007485312000168 [pii]

$10.1017 /$ S0007485312000168

Grosse-Wilde E, Kuebler LS, Bucks S, Vogel H, Wicher D, and Hansson BS. 2011. Antennal transcriptome of Manduca sexta. Proc Natl Acad Sci U S A 108:7449-7454. 1017963108 [pii]

10.1073/pnas.1017963108

Gu SH, Wu KM, Guo YY, Pickett JA, Field LM, Zhou JJ, and Zhang YJ. 2013. Identification of genes expressed in the sex pheromone gland of the black cutworm Agrotis ipsilon with putative roles in sex pheromone biosynthesis and transport. BMC Genomics 14:636. 1471-2164-14-636 [pii]

10.1186/1471-2164-14-636

Gu SH, Zhou JJ, Gao S, Wang DH, Li XC, Guo YY, and Zhang YJ. 2015. Identification and comparative expression analysis of odorant binding protein genes in the tobacco cutworm Spodoptera litura. Sci Rep 5:13800. 10.1038/srep13800

Guo W, Wang X, Ma Z, Xue L, Han J, Yu D, and Kang L. 2011. CSP and takeout genes modulate the switch between attraction and repulsion during behavioral phase change in the migratory locust. PLoS Genet 7:e1001291. 10.1371/journal.pgen.1001291

Ha TS, and Smith DP. 2006. A pheromone receptor mediates 11-cis-vaccenyl acetate-induced responses in Drosophila. J Neurosci 26:8727-8733. 10.1523/JNEUROSCI.0876-06.2006

He X, Tzotzos G, Woodcock C, Pickett JA, Hooper T, Field LM, and Zhou JJ. 2010. Binding of the general odorant binding protein of Bombyx mori BmorGOBP2 to the moth sex pheromone components. J Chem Ecol 36:1293-1305. 10.1007/s10886-010-9870-7

Hsu PD, Lander ES, and Zhang F. 2014. Development and applications of CRISPR-Cas9 for genome engineering. Cell 157:1262-1278. 10.1016/j.cell.2014.05.010

Hua JF, Zhang S, Cui JJ, Wang DJ, Wang CY, Luo JY, and Lv LM. 2012. Identification and binding characterization of three odorant binding proteins and one chemosensory protein from Apolygus lucorum (Meyer-Dur). J Chem Ecol 38:1163-1170. 10.1007/s10886-012-0178-7

Huang CX, Zhu LM, Ni JP, and Chao XY. 2002. A method of rearing the beet armyworm Spodoptera exigua Entomol Knowl 39:229-231.

Hull JJ, Perera OP, and Snodgrass GL. 2014. Cloning and expression profiling of odorant-binding proteins in the tarnished plant bug, Lygus lineolaris. Insect Mol Biol 23:78-97. 10.1111/imb.12064

Iovinella I, Bozza F, Caputo B, Della Torre A, and Pelosi P. 2013. Ligand-binding study of Anopheles gambiae chemosensory proteins. Chem Senses 38:409-419. bjt012 [pii]

10.1093/chemse/bjt012

Jacquin-Joly E, Vogt RG, Francois MC, and Nagnan-Le Meillour P. 2001. Functional and expression pattern analysis 
394

395

396

397

398

399

400

401

402

403

404

405

406

407

408

409

410

411

412

413

414

415

416

417

418

419

420

421

422

423

424

425

426

427

428

429

430

431

432

433

434 of chemosensory proteins expressed in antennae and pheromonal gland of Mamestra brassicae. Chem Senses 26:833-844.

Jeong YT, Shim J, Oh SR, Yoon HI, Kim CH, Moon SJ, and Montell C. 2013. An odorant-binding protein required for suppression of sweet taste by bitter chemicals. Neuron 79:725-737. 10.1016/j.neuron.2013.06.025

S0896-6273(13)00541-2 [pii]

Jiang XF, Luo LZ, Jiang YY, Zhang YJ, Zhang L, and Wang ZY. 2011. Damage characteristics and outbreak causes of Athetis lepigone in China. Plant Prot 37:130-133.

Jin JY, Li ZQ, Zhang YN, Liu NY, and Dong SL. 2014. Different roles suggested by sex-biased expression and pheromone binding affinity among three pheromone binding proteins in the pink rice borer, Sesamia inferens (Walker) (Lepidoptera: Noctuidae). J Insect Physiol 66:71-79. 10.1016/j.jinsphys.2014.05.013

S0022-1910(14)00088-2 [pii]

Karsholt O, van Nieukerken EJ, and de Jong YSDM. 2013. Lepidoptera, moths. Fauna Europaea version 2.6. [WWW document] URL: http://wwwfaunaeurorg.

Lagarde A, Spinelli S, Tegoni M, He X, Field L, Zhou JJ, and Cambillau C. 2011. The crystal structure of odorant binding protein 7 from Anopheles gambiae exhibits an outstanding adaptability of its binding site. $J \mathrm{Mol}$ Biol 414:401-412. 10.1016/j.jmb.2011.10.005

S0022-2836(11)01129-6 [pii]

Larter NK, Sun JS, and Carlson JR. 2016. Organization and function of Drosophila odorant binding proteins. Elife 5. 10.7554/eLife.20242

Lartigue A, Campanacci V, Roussel A, Larsson AM, Jones TA, Tegoni M, and Cambillau C. 2002. X-ray structure and ligand binding study of a moth chemosensory protein. I Biol Chem 277:32094-32098. 10.1074/jbc.M204371200

M204371200 [pii]

Leal WS. 2013. Odorant reception in insects: roles of receptors, binding proteins, and degrading enzymes. Annu Rev Entomol 58:373-391. 10.1146/annurev-ento-120811-153635

Leal WS, Nikonova L, and Peng G. 1999. Disulfide structure of the pheromone binding protein from the silkworm moth, Bombyx mori. FEBS Lett 464:85-90. S0014-5793(99)01683-X [pii]

Legeai F, Malpel S, Montagne N, Monsempes C, Cousserans F, Merlin C, Francois MC, Maibeche-Coisne M, Gavory F, Poulain J, and Jacquin-Joly E. 2011. An expressed sequence tag collection from the male antennae of the Noctuid moth Spodoptera littoralis: a resource for olfactory and pheromone detection research. BMC Genomics 12:86. 1471-2164-12-86 [pii]

10.1186/1471-2164-12-86

Li XM, Zhu XY, Wang ZQ, Wang Y, He P, Chen G, Sun L, Deng DG, and Zhang YN. 2015. Candidate chemosensory genes identified in Colaphellus bowringi by antennal transcriptome analysis. BMC Genomics 16:1028. 10.1186/s12864-015-2236-3

Li Y, Zhang J, Chen D, Yang P, Jiang F, Wang X, and Kang L. 2016. CRISPR/Cas9 in locusts: Successful establishment of an olfactory deficiency line by targeting the mutagenesis of an odorant receptor co-receptor (Orco). Insect Biochem Mol Biol 79:27-35. 10.1016/j.ibmb.2016.10.003

Li ZQ, Zhang S, Luo JY, Cui JJ, Ma Y, and Dong SL. 2013. Two Minus-C odorant binding proteins from Helicoverpa armigera display higher ligand binding affinity at acidic pH than neutral pH. J Insect Physiol 59:263-272. 10.1016/j.jinsphys.2012.12.004 
S0022-1910(12)00301-0 [pii]

Lindeborg M. 2008. Remarkable records of Macrolepidoptera in Sweden. Entomol Tidskr 129:43-52.

Liu N, Yang K, Liu Y, Xu W, Anderson A, and Dong S. 2015a. Two general-odorant binding proteins in Spodoptera litura are differentially tuned to sex pheromones and plant odorants. Comp Biochem Physiol A Mol Integr Physiol 180C:23-31. S1095-6433(14)00223-2 [pii]

10.1016/j.cbpa.2014.11.005

Liu NY, Liu CC, and Dong SL. 2013. Functional differentiation of pheromone-binding proteins in the common cutworm Spodoptera litura. Comp Biochem Physiol A Mol Integr Physiol 165:254-262. S10956433(13)00074-3 [pii]

10.1016/j.cbpa.2013.03.016

Liu NY, Yang F, Yang K, He P, Niu XH, Xu W, Anderson A, and Dong SL. 2015b. Two subclasses of odorant-binding proteins in Spodoptera exigua display structural conservation and functional divergence. Insect $\mathrm{Mol}$ Biol 24:167-182. 10.1111/imb.12143

Liu NY, Zhang T, Ye ZF, Li F, and Dong SL. 2015c. Identification and characterization of candidate chemosensory gene families from Spodoptera exigua developmental transcriptomes. Int J Biol Sci 11:1036-1048. $10.7150 /$ ijbs. 12020

Liu X, Luo Q, Zhong G, Rizwan-Ul-Haq M, and Hu M. 2010. Molecular characterization and expression pattern of four chemosensory proteins from diamondback moth, Plutella xylostella (Lepidoptera: Plutellidae). J Biochem 148:189-200. mvq050 [pii]

10.1093/jb/mvq050

Liu Y, Gu S, Zhang Y, Guo Y, and Wang G. 2012. Candidate olfaction genes identified within the Helicoverpa armigera antennal transcriptome. PLoS One 7:e48260. 10.1371/journal.pone.0048260

PONE-D-12-23655 [pii]

Liu YL, Guo H, Huang LQ, Pelosi P, and Wang CZ. 2014. Unique function of a chemosensory protein in the proboscis of two Helicoverpa species. J Exp Biol 217:1821-1826. 10.1242/jeb.102020

Ma JF, Li LT, Gan YJ, and Dong ZP. 2012. The research on annual life history and natural enemy species of Athetis lepigone CHINA PLANT PROTECTION 32:37-40.

Maleszka J, Foret S, Saint R, and Maleszka R. 2007. RNAi-induced phenotypes suggest a novel role for a chemosensory protein CSP5 in the development of embryonic integument in the honeybee (Apis mellifera). Dev Genes Evol 217:189-196. 10.1007/s00427-006-0127-y

Maleszka R, and Stange G. 1997. Molecular cloning, by a novel approach, of a cDNA encoding a putative olfactory protein in the labial palps of the moth Cactoblastis cactorum. Gene 202:39-43. S0378-1119(97)00448-4 [pii]

McKenna MP, Hekmat-Scafe DS, Gaines P, and Carlson JR. 1994. Putative Drosophila pheromone-binding proteins expressed in a subregion of the olfactory system. J Biol Chem 269:16340-16347.

McKenzie SK, Oxley PR, and Kronauer DJ. 2014. Comparative genomics and transcriptomics in ants provide new insights into the evolution and function of odorant binding and chemosensory proteins. BMC Genomics 15:718. 10.1186/1471-2164-15-718

1471-2164-15-718 [pii]

Missbach C, Vogel H, Hansson BS, and Grobetae-Wilde E. 2015. Identification of odorant binding proteins and chemosensory proteins in antennal transcriptomes of the jumping bristletail Lepismachilis y-signata and 
476

477

478

479

480

481

482

483

484

485

486

487

488

489

490

491

492

493

494

495

496

497

498

499

500

501

502

503

504

505

506

507

508

509

510

511

512

513

514

515

516

the firebrat Thermobia domestica: evidence for an independent OBP-OR origin. Chem Senses 40:615-626. 10.1093/chemse/bjv050

Muller PY, Janovjak H, Miserez AR, and Dobbie Z. 2002. Processing of gene expression data generated by quantitative real-time RT-PCR. Biotechniques 32:1372-1374, 1376, 1378-1379.

Nikolaevitch PA, and Vjatcheslavovna IE. 2003. The Noctuidae (Lepidoptera) of the Daghestan Republic (Russia) II. Phegea 31:167-181.

Nomura A, Kawasaki K, Kubo T, and Natori S. 1992. Purification and localization of p10, a novel protein that increases in nymphal regenerating legs of Periplaneta americana (American cockroach). Int J Dev Biol 36:391-398.

Paula DP, Togawa RC, Costa MM, Grynberg P, Martins NF, and Andow DA. 2016. Identification and expression profile of odorant-binding proteins in Halyomorpha halys (Hemiptera: Pentatomidae). Insect Mol Biol 25:580-594. 10.1111/imb.12243

Pelosi P, Calvello M, and Ban L. 2005. Diversity of odorant-binding proteins and chemosensory proteins in insects. Chem Senses 30 Suppl 1:i291-292. 30/suppl_1/i291 [pii]

10.1093/chemse/bjh229

Pelosi P, lovinella I, Felicioli A, and Dani FR. 2014a. Soluble proteins of chemical communication: an overview across arthropods. Front Physiol 5:320. 10.3389/fphys.2014.00320

Pelosi P, and Maida R. 1995. Odorant-binding proteins in insects. Comparative Biochemistry and Physiology Part B, Biochemistry and Molecular Biology 111:503-514.

Pelosi P, Mastrogiacomo R, lovinella I, Tuccori E, and Persaud KC. 2014b. Structure and biotechnological applications of odorant-binding proteins. Appl Microbiol Biotechnol 98:61-70. 10.1007/s00253-013-5383-y

Petersen TN, Brunak S, von Heijne G, and Nielsen H. 2011. SignalP 4.0: discriminating signal peptides from transmembrane regions. Nat Methods 8:785-786. 10.1038/nmeth.1701

nmeth.1701 [pii]

Picimbon JF, Dietrich K, Krieger J, and Breer H. 2001. Identity and expression pattern of chemosensory proteins in Heliothis virescens (Lepidoptera, Noctuidae). Insect Biochem Mol Biol 31:1173-1181. S0965174801000637 [pii]

Qiao H, Tuccori E, He X, Gazzano A, Field L, Zhou JJ, and Pelosi P. 2009. Discrimination of alarm pheromone (E)beta-farnesene by aphid odorant-binding proteins. Insect Biochem Mol Biol 39:414-419. 10.1016/j.ibmb.2009.03.004

S0965-1748(09)00055-1 [pii]

Qiao HL, Deng PY, Li DD, Chen M, Jiao ZJ, Liu ZC, Zhang YZ, and Kan YC. 2013. Expression analysis and binding experiments of chemosensory proteins indicate multiple roles in Bombyx mori. J Insect Physiol 59:667-675. 10.1016/j.jinsphys.2013.04.004

S0022-1910(13)00096-6 [pii]

Schultze A, Schymura D, Forstner M, and Krieger J. 2012. Expression pattern of a 'Plus-C' class odorant binding protein in the antenna of the malaria vector Anopheles gambiae. Insect Mol Biol 21:187-195. 10.1111/j.1365-2583.2011.01125.x

Shi J, Wang ZY, Jiang YY, Shan XN, Zhang HJ, Wang J, and Ge X. 2011. Preliminary report on investigation of the overwintering sites of Athetis lepigone. Plant Prot 37:138-140.

Simon P. 2003. Q-Gene: processing quantitative real-time RT-PCR data. Bioinformatics 19:1439-1440. 
517

518

519

520

521

522

523

524

525

526

527

528

529

530

531

532

533

534

535

536

537

538

539

540

541

542

543

544

545

546

547

548

549

550

551

552

553

554

555

556

557

10.1093/bioinformatics/btg157

Spinelli S, Lagarde A, lovinella I, Legrand P, Tegoni M, Pelosi P, and Cambillau C. 2012. Crystal structure of Apis mellifera OBP14, a C-minus odorant-binding protein, and its complexes with odorant molecules. Insect Biochem Mol Biol 42:41-50. 10.1016/j.ibmb.2011.10.005

S0965-1748(11)00192-5 [pii]

Stowers L, and Logan DW. 2008. LUSH shapes up for a starring role in olfaction. Cell 133:1137-1139. 10.1016/j.cell.2008.06.010

Sun H, Song Y, Du J, Wang X, and Cheng Z. 2016. Identification and tissue distribution of chemosensory protein and odorant binding protein genes in Athetis dissimilis (Lepidoptera: Noctuidae). Appl Entomol Zool 51:409420.

Sun L, Zhou JJ, Gu SH, Xiao HJ, Guo YY, Liu ZW, and Zhang YJ. 2015. Chemosensillum immunolocalization and ligand specificity of chemosensory proteins in the alfalfa plant bug Adelphocoris lineolatus (Goeze). Sci Rep 5:8073. 10.1038/srep08073

srep08073 [pii]

Sun M, Liu Y, and Wang G. 2013. Expression patterns and binding properties of three pheromone binding proteins in the diamondback moth, Plutella xyllotella. J Insect Physiol 59:46-55. 10.1016/j.jinsphys.2012.10.020

Swarup S, Morozova TV, Sridhar S, Nokes M, and Anholt RR. 2014. Modulation of feeding behavior by odorantbinding proteins in Drosophila melanogaster. Chem Senses 39:125-132. 10.1093/chemse/bjt061

Vogt RG. 2005. Molecular Basis of Pheromone Detection in Insects. In Comprehensive Insect Physiology, Biochemistry, Pharmacology and Molecular BiologyVolume 3 Endocrinology (LI Gilbert, K latro, SS Gill eds):pp. 753-804. Elsevier, London. ISBN: 044451516X.

Vogt RG, and Riddiford LM. 1981. Pheromone binding and inactivation by moth antennae. Nature 293:161-163.

Vogt RG, Rybczynski R, and Lerner MR. 1991. Molecular cloning and sequencing of general odorant-binding proteins GOBP1 and GOBP2 from the tobacco hawk moth Manduca sexta: comparisons with other insect OBPs and their signal peptides. J Neurosci 11:2972-2984.

Wanner KW, Willis LG, Theilmann DA, Isman MB, Feng Q, and Plettner E. 2004. Analysis of the insect os-d-like gene family. J Chem Ecol 30:889-911.

Xiu WM, and Dong SL. 2007. Molecular characterization of two pheromone binding proteins and quantitative analysis of their expression in the beet armyworm, Spodoptera exigua Hübner. J Chem Ecol 33:947-961. 10.1007/s10886-007-9277-2

Zhang J, Wang B, Dong S, Cao D, Dong J, Walker WB, Liu Y, and Wang G. 2015a. Antennal transcriptome analysis and comparison of chemosensory gene families in two closely related noctuidae moths, Helicoverpa armigera and H. assulta. PLoS One 10:e0117054. 10.1371/journal.pone.0117054

PONE-D-14-43348 [pii]

Zhang LW, Kang K, Jiang SC, Zhang YN, Wang TT, Zhang J, Sun L, Yang YQ, Huang CC, Jiang LY, and Ding DG. 2016 . Analysis of the antennal transcriptome and insights into olfactory genes in Hyphantria cunea (Drury). PLoS One 11:e0164729. 10.1371/journal.pone.0164729

Zhang YN, Jin JY, Jin R, Xia YH, Zhou JJ, Deng JY, and Dong SL. 2013. Differential expression patterns in chemosensory and non-chemosensory tissues of putative chemosensory genes identified by transcriptome analysis of insect pest the purple stem borer Sesamia inferens (Walker). PLoS One 8:e69715. 10.1371/journal.pone.0069715 
558

559

560

561

562

563

564

565

566

567

568

569

570

571

572

573

574

575

576

577

578

579

580

581

582

583
Zhang YN, Ma JF, Sun L, Dong ZP, Li ZQ, Zhu XY, Wang Y, Wang L, Deng DG, and Li JB. 2016b. Molecular identification and sex distribution of two chemosensory receptor families in Athetis lepigone by antennal transcriptome analysis. J Asia-Pac Entomol 19:571-580.

Zhang YN, Ye ZF, Yang K, and Dong SL. 2014. Antenna-predominant and male-biased CSP19 of Sesamia inferens is able to bind the female sex pheromones and host plant volatiles. Gene 536:279-286. 10.1016/j.gene.2013.12.011

S0378-1119(13)01672-7 [pii]

Zhang YN, Zhu XY, Fang LP, He P, Wang ZQ, Chen G, Sun L, Ye ZF, Deng DG, and Li JB. 2015b. Identification and expression profiles of sex pheromone biosynthesis and transport related genes in Spodoptera litura. PLoS One 10:e0140019. 10.1371/journal.pone.0140019

Zhang ZL, Zhao Y, and Ding XY. 2009. Shenyang insect illustrated handbook. Shenyang: Liaoning National Publishing House:258.

Zhou JJ. 2010. Odorant-binding proteins in insects. Vitam Horm 83:241-272. S0083-6729(10)83010-9 [pii]

10.1016/S0083-6729(10)83010-9

Zhou JJ, Robertson G, He X, Dufour S, Hooper AM, Pickett JA, Keep NH, and Field LM. 2009. Characterisation of Bombyx mori Odorant-binding proteins reveals that a general odorant-binding protein discriminates between sex pheromone components. J Mol Biol 389:529-545. S0022-2836(09)00429-X [pii]

10.1016/j.jmb.2009.04.015

Zhou JJ, Zhang GA, Huang W, Birkett MA, Field LM, Pickett JA, and Pelosi P. 2004. Revisiting the odorant-binding protein LUSH of Drosophila melanogaster: evidence for odour recognition and discrimination. FEBS Lett 558:23-26. 10.1016/S0014-5793(03)01521-7

Zhu GH, Xu J, Cui Z, Dong XT, Ye ZF, Niu DJ, Huang YP, and Dong SL. 2016. Functional characterization of SlitPBP3 in Spodoptera litura by CRISPR/Cas9 mediated genome editing. Insect Biochem Mol Biol 75:1-9. 10.1016/j.ibmb.2016.05.006 
584 Tables Legends:

585 Table 1. The BLASTX match of OBP genes in A. lepigone.

586

587

588

589

590

591

592

593

\section{Table 2. The BLASTX match of CSP genes in A. lepigone.}

\section{Figure Legends:}

Fig. 1. Phylogenetic tree of moth OBPs. The A. lepigone translated genes are shown in blue. This tree was constructed using phyML based on alignment results of MAFFT. Al: A. lepigone, Bm: B. mori, Si: S. inferens, Sl: S. littorali, Ms: M. sexta.

Fig. 2. Phylogenetic tree of moth CSPs. The A. lepigone translated genes are shown in blue. This tree was constructed using phyML based on alignment results of MAFFT. Al: A. lepigone, Bm: B. mori, Si: S. inferens, S1: S. littorali, Ms: M. sexta.

Fig. 3. Expression patterns of OBP genes in A. lepigone. The relative expression level is indicated as mean $\pm \mathrm{SE}(\mathrm{N}=3)$. Different capital letters mean significant difference between tissues ( $p<0.05$, ANOVA, LSD). FA, female antennae; MA, male antennae; Pr, proboscises; Ab, abdomen; Le, legs; Wi, wings.

Fig. 4. Expression patterns of CSP genes in A. lepigone. The relative expression level is indicated as mean $\pm \mathrm{SE}(\mathrm{N}=3)$. Different capital letters mean significant difference between tissues ( $p<0.05$, ANOVA, LSD). FA, female antennae; MA, male antennae; Pr, proboscises; $\mathrm{Ab}$, abdomen; Le, legs; Wi, wings.

\section{Supplemental Information}

Table S1. Amino acid sequences of AIOBPs and AICSPs obtained in the study.

Table S2. Primers used for qRT-PCR.

Fig. S1. Multiple alignment of AlOBPs.

Fig. S2. Multiple alignment of AICSPs. 


\section{Table 1 (on next page)}

Table 1. The BLASTX match of OBP genes in A. lepigone 
Table 1. The BLASTX match of OBP genes in A. lepigone.

\begin{tabular}{|c|c|c|c|c|c|c|c|c|}
\hline \multirow{2}{*}{$\begin{array}{l}\text { Gene } \\
\text { Name }\end{array}$} & \multirow{2}{*}{$\begin{array}{l}\text { ORF } \\
\text { (aa) }\end{array}$} & \multirow{2}{*}{$\begin{array}{c}\text { Signal } \\
\text { Peptide }\end{array}$} & \multirow{2}{*}{$\begin{array}{c}\text { Complete } \\
\text { ORF }\end{array}$} & \multicolumn{5}{|c|}{ Best Blastx Match } \\
\hline & & & & Name & Acc. No. & Species & E value & Identity (\%) \\
\hline GOBP1 & 163 & $1-18$ & $\mathrm{Y}$ & general odorant binding protein 1 & ABI24160.1 & Agrotis ipsilon & $8.00 \mathrm{E}-83$ & 95 \\
\hline GOBP2 & 162 & $1-21$ & $\mathrm{Y}$ & general odorant binding protein 2 & AHC72380.1 & Sesamia inferens & $2.00 \mathrm{E}-92$ & 91 \\
\hline PBP1 & 167 & $1-23$ & $\mathrm{Y}$ & pheromone binding protein 1 precursor & AAC05702.2 & Mamestra brassicae & $3.00 \mathrm{E}-88$ & 90 \\
\hline PBP2 & 170 & $1-24$ & $\mathrm{Y}$ & pheromone binding protein 2 precursor & AAC05701.2 & Mamestra brassicae & $5.00 \mathrm{E}-58$ & 90 \\
\hline РBP3 & 164 & $1-22$ & Y & pheromone-binding protein 3 & AFM36758.1 & Agrotis ipsilon & $2.00 \mathrm{E}-85$ & 90 \\
\hline OBP1 & 116 & $\mathrm{~N}$ & $\mathrm{~N}$ & SexiOBP14 & AGP03460.1 & Spodoptera exigua & $7.00 \mathrm{E}-54$ & 88 \\
\hline OBP2 & 146 & $1-17$ & $\mathrm{Y}$ & odorant binding protein 6 & AGR39569.1 & Agrotis ipsilon & $2.00 \mathrm{E}-84$ & 88 \\
\hline OBP3 & 120 & $\mathrm{~N}$ & $\mathrm{~N}$ & odorant binding protein 8 & AKI87969.1 & Spodoptera litura & $5.00 \mathrm{E}-79$ & 85 \\
\hline OBP4 & 138 & $1-16$ & $\mathrm{Y}$ & odorant-binding protein 18 & AFI57167.1 & Helicoverpa armigera & $2.00 \mathrm{E}-52$ & 85 \\
\hline OBP5 & 147 & $1-21$ & $\mathrm{Y}$ & pheromone binding protein 4 & AAL66739.1 & Mamestra brassicae & $1.00 \mathrm{E}-81$ & 84 \\
\hline OBP6 & 134 & $1-17$ & Y & ABPX & AGS36754.1 & Sesamia inferens & $2.00 \mathrm{E}-54$ & 83 \\
\hline OBP7 & 203 & $1-20$ & $\mathrm{Y}$ & odorant-binding protein 19 & AGC92793.1 & Helicoverpa assulta & $2.00 \mathrm{E}-69$ & 83 \\
\hline OBP8 & 147 & $1-20$ & $\mathrm{Y}$ & oderant binding protein 6 & AFM77984.1 & Spodoptera exigua & $4.00 \mathrm{E}-56$ & 82 \\
\hline OBP9 & 133 & $1-16$ & Y & odorant binding protein 9 & AGH70105.1 & Spodoptera exigua & $5.00 \mathrm{E}-84$ & 80 \\
\hline OBP10 & 96 & $\mathrm{~N}$ & $\mathrm{~N}$ & odorant binding protein 1 & AGR39564.1 & Agrotis ipsilon & $2.00 \mathrm{E}-58$ & 79 \\
\hline OBP5 & 147 & $1-21$ & $\mathrm{Y}$ & pheromone binding protein 4 & AAL66739.1 & Mamestra brassicae & $1.00 \mathrm{E}-81$ & 84 \\
\hline OBP11 & 152 & $1-21$ & $\mathrm{Y}$ & pheromone binding protein 4 & AAL66739.1 & Mamestra brassicae & $1.00 \mathrm{E}-30$ & 78 \\
\hline OBP12 & 141 & $1-26$ & $\mathrm{Y}$ & odorant binding protein 8 & AGH70104.1 & Spodoptera exigua & $9.00 \mathrm{E}-78$ & 77 \\
\hline OBP13 & 184 & $1-20$ & Y & odorant binding protein & AII00978.1 & Dendrolimus houi & $1.00 \mathrm{E}-106$ & 75 \\
\hline OBP14 & 186 & $1-17$ & $\mathrm{Y}$ & odorant binding protein 1 & AGR39564.1 & Agrotis ipsilon & 8.00E-97 & 75 \\
\hline OBP 15 & 155 & $1-24$ & $\mathrm{Y}$ & SexiOBP11 & AGP03457.1 & Spodoptera exigua & $2.00 \mathrm{E}-82$ & 73 \\
\hline OBP16 & 148 & $1-21$ & Y & OBP7 & AEB54591.1 & Helicoverpa armigera & $7.00 \mathrm{E}-54$ & 70 \\
\hline OBP17 & 246 & $1-19$ & $\mathrm{Y}$ & odorant binding protein & AII00994.1 & Dendrolimus kikuchii & $2.00 \mathrm{E}-74$ & 67 \\
\hline OBP18 & 149 & $1-22$ & $\mathrm{Y}$ & OBP5 & AEB54581.1 & Helicoverpa armigera & $8.00 \mathrm{E}-58$ & 65 \\
\hline OBP19 & 71 & $1-22$ & $\mathrm{~N}$ & OBP6 & AGS36748.1 & Sesamia inferens & $2.00 \mathrm{E}-25$ & 65 \\
\hline
\end{tabular}




\begin{tabular}{|c|c|c|c|c|c|c|c|c|}
\hline OBP20 & 170 & $1-23$ & Y & odorant binding protein 4 & AKI87965.1 & Spodoptera litura & $2.00 \mathrm{E}-76$ & 61 \\
\hline OBP21 & 153 & $1-21$ & Y & SexiOBP9 & AGP03455.1 & Spodoptera exigua & $2.00 \mathrm{E}-77$ & 59 \\
\hline OBP22 & 146 & $1-25$ & Y & SexiOBP12 & AGP03458.1 & Spodoptera exigua & $1.00 \mathrm{E}-72$ & 58 \\
\hline OBP23 & 145 & $1-17$ & Y & odorant binding protein & ADY 17886.1 & Spodoptera exigua & $1.00 \mathrm{E}-85$ & 40 \\
\hline
\end{tabular}


Table 2 (on next page)

Table 2. The BLASTX match of CSP genes in A. lepigone 
Table 2. The BLASTX match of CSP genes in A. lepigone.

\begin{tabular}{|c|c|c|c|c|c|c|c|c|}
\hline \multirow{2}{*}{$\begin{array}{l}\text { Gene } \\
\text { Name }\end{array}$} & \multirow{2}{*}{$\begin{array}{l}\text { ORF } \\
\text { (aa) }\end{array}$} & \multirow{2}{*}{$\begin{array}{c}\text { Signal } \\
\text { Peptide }\end{array}$} & \multirow{2}{*}{$\begin{array}{c}\text { Complete } \\
\text { ORF }\end{array}$} & \multicolumn{5}{|c|}{ Best Blastx Match } \\
\hline & & & & Name & Acc. No. & Species & E value & Identity (\%) \\
\hline CSP1 & 124 & $1-16$ & $\mathrm{Y}$ & chemosensory protein 15 & AGH20053.1 & Helicoverpa armigera & $5.00 \mathrm{E}-62$ & 83 \\
\hline CSP2 & 124 & $1-15$ & Y & chemosensory protein precursor & NP_001037066.1 & Bombyx mori & $2.00 \mathrm{E}-38$ & 61 \\
\hline CSP3 & 122 & $1-18$ & $\mathrm{Y}$ & ejaculatory bulb-specific protein 3-like & XP_012549936.1 & Bombyx mori & $2.00 \mathrm{E}-45$ & 74 \\
\hline CSP4 & 294 & $1-16$ & $\mathrm{Y}$ & chemosensory protein & AIW65104.1 & Helicoverpa armigera & $2.00 \mathrm{E}-130$ & 78 \\
\hline CSP5 & 56 & $\mathrm{~N}$ & $\mathrm{~N}$ & chemosensory protein & AII01011.1 & Dendrolimus houi & $3.00 \mathrm{E}-17$ & 62 \\
\hline CSP6 & 150 & $1-19$ & Y & putative chemosensory protein & AGY49270.1 & Sesamia inferens & $6.00 \mathrm{E}-72$ & 78 \\
\hline CSP7 & 114 & $1-19$ & Y & sensory appendage protein-like protein & AAK14793.1 & Mamestra brassicae & $1.00 \mathrm{E}-28$ & 61 \\
\hline CSP8 & 127 & $1-18$ & $\mathrm{Y}$ & chemosensory protein 6 & AGR39576.1 & Agrotis ipsilon & $5.00 \mathrm{E}-63$ & 91 \\
\hline CSP9 & 127 & $1-16$ & Y & chemosensory protein & AAF71289.1 & Mamestra brassicae & $3.00 \mathrm{E}-59$ & 83 \\
\hline CSP10 & 123 & $1-18$ & Y & chemosensory protein 8 & AGR39578.1 & Agrotis ipsilon & 4.00E-68 & 85 \\
\hline CSP11 & 123 & $1-16$ & $\mathrm{Y}$ & chemosensory protein & AIW65100.1 & Helicoverpa armigera & $2.00 \mathrm{E}-65$ & 76 \\
\hline CSP12 & 128 & $1-18$ & Y & chemosensory protein CSP2 & ABM67689.1 & Spodoptera exigua & 4.00E-70 & 81 \\
\hline CSP13 & 123 & $1-19$ & Y & chemosensory protein & AIX97829.1 & Cnaphalocrocis medinalis & $1.00 \mathrm{E}-56$ & 81 \\
\hline CSP14 & 46 & $\mathrm{~N}$ & $\mathrm{~N}$ & putative chemosensory protein & AGY49260.1 & Sesamia inferens & $3.00 \mathrm{E}-25$ & 100 \\
\hline CSP15 & 122 & $1-16$ & Y & chemosensory protein 10 & AFR92094.1 & Helicoverpa armigera & $1.00 \mathrm{E}-73$ & 89 \\
\hline CSP16 & 130 & $\mathrm{~N}$ & Y & chemosensory protein 15 & NP_001091781.1 & Bombyx mori & $3.00 \mathrm{E}-42$ & 59 \\
\hline CSP17 & 127 & $1-18$ & Y & putative chemosensory protein & AGY49267.1 & Sesamia inferens & $1.00 \mathrm{E}-70$ & 81 \\
\hline CSP18 & 123 & $1-18$ & $\mathrm{Y}$ & chemosensory protein 8 & AFR92092.1 & Helicoverpa armigera & $8.00 \mathrm{E}-43$ & 74 \\
\hline CSP19 & 120 & $1-16$ & Y & chemosensory protein 4 & AGR39574.1 & Agrotis ipsilon & $1.00 \mathrm{E}-60$ & 79 \\
\hline CSP20 & 107 & $1-18$ & $\mathrm{Y}$ & chemosensory protein 5 & AGR39575.1 & Agrotis ipsilon & $4.00 \mathrm{E}-53$ & 97 \\
\hline
\end{tabular}


Figure 1

Fig. 1. Phylogenetic tree of moth OBPs

The $A$. lepigone translated genes are shown in blue. This tree was constructed using phyML based on alignment results of MAFFT. Al: A. lepigone, Bm: B. mori, Si: S. inferens, SI: S. littorali, Ms: M. sexta.

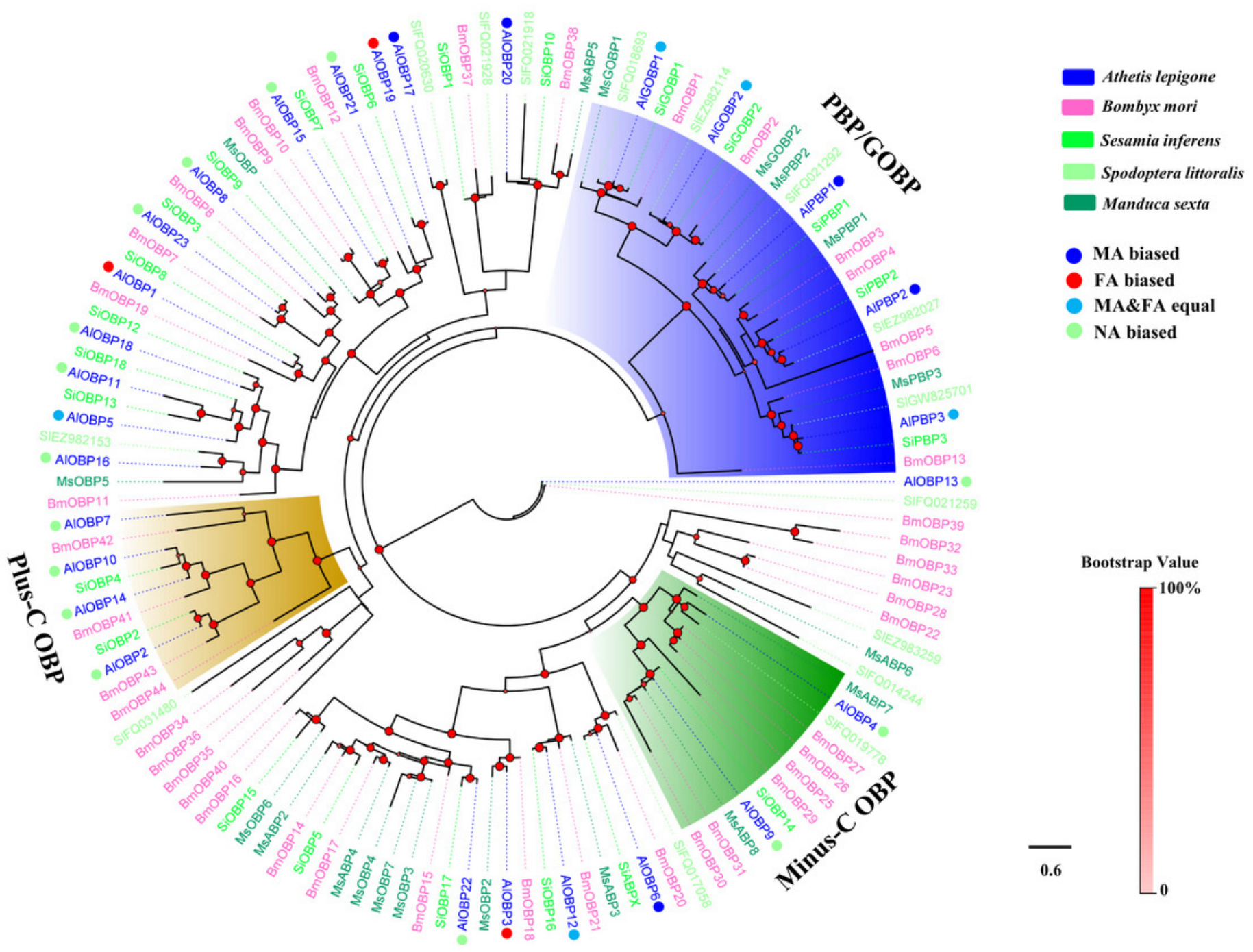


Figure 2

Fig. 2. Phylogenetic tree of moth CSPs

The $A$. lepigone translated genes are shown in blue. This tree was constructed using phyML based on alignment results of MAFFT. Al: A. lepigone, Bm: B. mori, Si: S. inferens, SI: S. littorali, Ms: M. sexta.

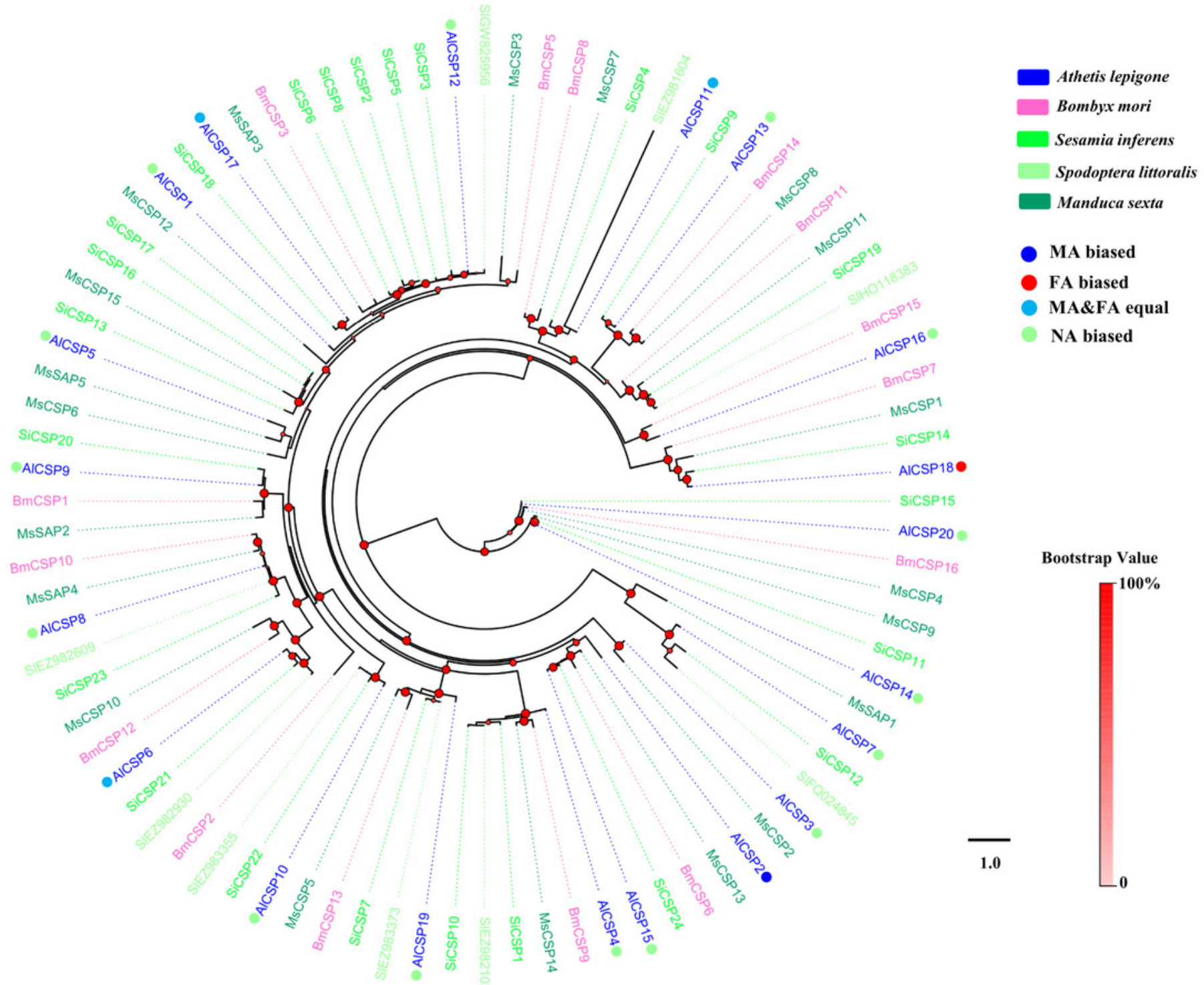




\section{Figure 3}

Fig. 3. Expression patterns of OBP genes in A. lepigone

The relative expression level is indicated as mean $\pm \mathrm{SE}(\mathrm{N}=3)$. Different capital letters mean significant difference between tissues $) p<0.05$, ANOVA, LSD). FA, female antennae; MA, male antennae; Pr, proboscises; Ab, abdomen; Le, legs; Wi, wings. 

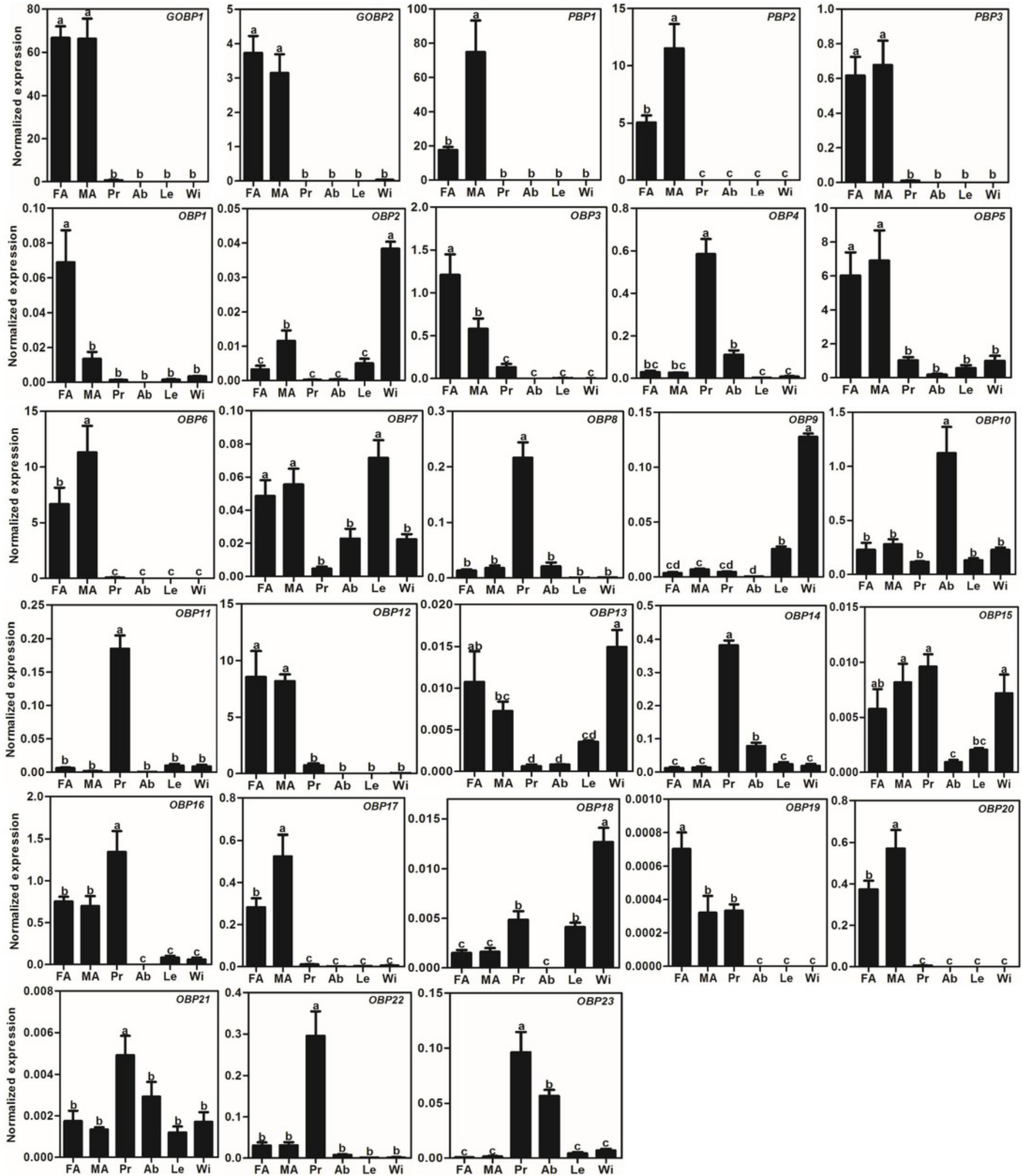


\section{Figure 4}

Fig. 4. Expression patterns of CSP genes in A. lepigone

The relative expression level is indicated as mean $\pm \mathrm{SE}(\mathrm{N}=3)$. Different capital letters mean significant difference between tissues $) p<0.05$, ANOVA, LSD). FA, female antennae; MA, male antennae; Pr, proboscises; Ab, abdomen; Le, legs; Wi, wings.
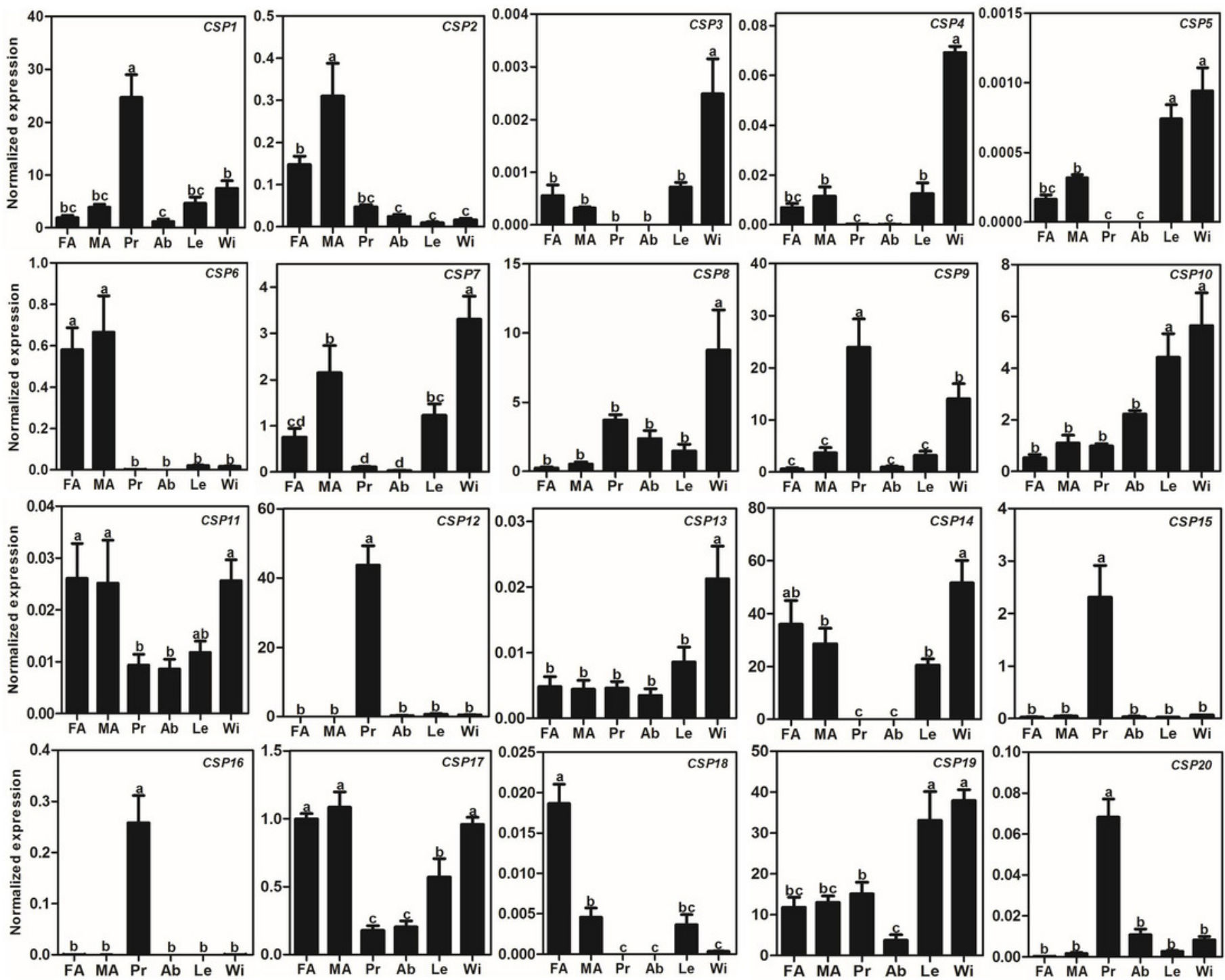